\title{
The Influence of Clan Surname Diversity on County Economic Development Performance in China: An Empirical Study Based on Chinese Genealogy Data
}

\author{
Huiyun Zhang \\ Jinan University, Guangzhou, China \\ Email: jitime2019@126.com
}

How to cite this paper: Zhang, H.Y. (2019) The Influence of Clan Surname Diversity on County Economic Development Performance in China: An Empirical Study Based on Chinese Genealogy Data. Modern Economy, 10, 1073-1089. https://doi.org/10.4236/me.2019.104072

Received: January 11, 2019

Accepted: April 6, 2019

Published: April 9, 2019

Copyright () 2019 by author(s) and Scientific Research Publishing Inc. This work is licensed under the Creative Commons Attribution International License (CC BY 4.0).

http://creativecommons.org/licenses/by/4.0/ (c) (i) Open Access

\begin{abstract}
Culture is considered to be a deep-seated factor affecting economic development, among which the economic impact of cultural diversity has attracted considerable attention. At the county level, clans play an important cultural and social role. Although traditional clans in China are influenced by Confucianism, different clans have different cultural inheritance. Genealogy, ancestral precepts and clan rules are the carriers of each clan's ideological inheritance. Different clans are distinguished by surnames, and cultural backgrounds and concepts are quite diverse. This paper will examine the impact of this diversity on the performance of county economic development. This paper collects the data of the Chinese Genealogy published by the Shanghai Library, collates and constructs the number of clan surnames and the diversity index of clan surnames in 1087 counties, and uses the night light brightness data released by the National Oceanic and Atmospheric Administration (NOAA) to measure the economic development performance of counties in China. Empirical results show that the diversity of clan surnames has a significant positive impact on the performance of county economic development, which remains stable in the test. The more diverse the clan surnames are, the better the economic development performance of counties will be.
\end{abstract}

\section{Keywords}

Clan Surnames, Cultural Diversity, Economic Development Performance

\section{Introduction}

Economic development is closely related to human life. The study of economic 
development and development gap between countries and regions has always been an important topic in economic literature. Traditional economic theory holds that the main factors affecting the performance of economic development are capital, labor force and other factors of production, as well as technological level and system. The differences of these factors lead to the differences of regional economic development level, and there are many empirical studies in this regard. But in the long-term evolution history, these factors are relatively easy to change. Therefore, the three factors that influence economic development in traditional analysis are not enough to explain the whole history of national and regional economic development and the gap between the rich and the poor (Luo Hao, 2009) [1]. Culture, which has accumulated and settled down gradually since the development of human beings, is a relatively fixed belief and value (Guiso et al., 2006) [2]. Culture has a profound impact on people's behavioral concepts, which is a deeper factor affecting economic development performance (Pan Yue et al., 2017) [3].

As for the study of culture and economy, the early literature is analyzed from the theoretical aspect. It was Weber who put forward this earlier. Weber (1904) [4] pointed out that the doctrine respected by Protestants in Western Europe gave birth to the spirit of capitalism, thus promoting the economic development of Western society. Since the 1990s, many scholars have begun to analyze the impact of culture on national or regional economy through empirical analysis. In recent years, more and more scholars have paid attention to the economic impact of cultural diversity, and empirical research has both advantages and disadvantages. Cultural diversity includes the diversity brought about by different races, religions, languages and birthplaces. Most foreign scholars pay attention to the impact of ethnic and linguistic diversity on the economy. China is vast in territory and has a history of more than two thousand years. Due to geographical distance and ethnic diversity, cultural diversity is a basic feature of Chinese culture and plays a profound role in economic development. In the specific context of China, the diversity of languages in cultural diversity has attracted more attention from domestic scholars. Dialect data have been used as indicators for empirical analysis of cultural diversity in recent years (Xu Xianxiang et al., 2015; Pan Yue et al., 2017; Li Guangqin et al., 2017) [3] [5] [6]. Xu Xianxiang et al. (2015) [5] studied the influence of dialect diversity on the economic growth of cities at prefecture level and above. Empirical results show that diversity hinders the economic growth of cities. Li Guangqin et al. (2017) [6] believe that linguistic diversity is not conducive to the improvement of regional openness. Pan Yue et al. (2017) [3] believe that cultural diversity is conducive to the exchange and collision of people from different backgrounds, resulting in a relaxed cultural atmosphere, which is conducive to enterprise innovation. These previous studies have emphasized the important influence of cultural diversity on China's economic development.

China's culture has a long history of more than two thousand years, and the 
traditional culture still has a profound impact on people's behavior concept. The concept of clan is an important aspect of traditional culture which is well inherited and has an impact on economic development. Patriarchal clan organizations, established and continued by blood relationship, play an important role in the social network in rural areas of China, which is conducive to promoting private lending transactions (Guo Yunnan et al., 2013) [7]. Guo Yunnan et al. (2014) [8] used ancestral temples and genealogy numbers to measure clans. Empirical research found that clan network would narrow the income distribution gap in rural areas. Zhang (2016) [9] measured the strength of clan culture by the number of genealogies per 10,000 people in cities of China, and empirically tested the relationship between clan culture and private economic development. These studies analyzed the impact of clans on economy from different aspects, but in the measurement of clans, all clans in the region were measured uniformly, without subdividing the impact of the distribution of different clans in the region on economic development. Different clans have different family discipline and family rules. They advocate different cultural emphases. Some value moral cultivation and some value business. The impact of these clan differences on the economy is uncertain. In addition, as an organization based on consanguinity, clan advocates the mutual promotion and common development of members within clan, forming a special trust different from the general trust of society. The trust scope of this special trust is relatively small, which will have a negative impact on regional business development, innovation and entrepreneurship, and the development of modern civilization (Greif and Tabellini, 2017) [10]. Therefore, from the perspective of cultural diversity, this paper will further subdivide different clans with clan surnames, and measure the impact of clan surname diversity on county economic development performance.

In short, in recent years, the economic impact of cultural diversity has attracted considerable attention. The empirical literature in this regard mostly studies the impact of diversity of languages on economic development, and there is no empirical study on economic development from the perspective of clan surname diversity. This paper will empirically analyze the impact of clan surname diversity on county economic development performance at the county level.

\section{Literature Review and Concept Definition}

\subsection{Cultural Diversity: Definition of the Concept of Clan Surname Diversity}

The Convention on the Protection and Promotion of the Diversity of Cultural Expressions clearly defines the concept of cultural diversity- "various forms of cultural expression by various groups and societies". From this definition, we can see that the carrier of cultural diversity is first of all human beings, different groups and different societies are the basic conditions for cultural diversity, and different forms of cultural expression are the direct manifestation of cultural diversity. Every country and region in the world has its own unique culture, which 
is the most basic content of cultural diversity. Obviously, understanding the connotation of cultural diversity needs to clarify the connotation of culture first.

The concept of culture is very extensive and rich in connotation. It is the collective name of various forms of human life elements. It has different concepts because of different times, perspectives and different research purposes. There are different opinions on the concept of culture, and there is no accepted accuracy definition of it. A relatively common understanding is that culture is a general term for the elements accumulated from various acts and spiritual activities in people's lives for thousands of years. The concept of culture can be divided into broad sense and narrow sense. The broad concept refers to "all material and spiritual wealth created by human beings in the practice of historical life", while the narrow concept holds that culture is "the sum of the spiritual life forms that take place and accumulate on the basis of material conditions and social production and life style". Among them, the early classical definition of narrow culture was put forward by British scholar Taylor. He believed that culture was a complex whole, including the ability and habit acquired by individuals in social life, and the common spiritual products of human beings such as knowledge, art, law and belief.

In economics, theoretical research and empirical research define different connotations of culture. In terms of theoretical research, culture is defined as a belief formed by the recognition of the results of human behavior, which may be modified by the previous generation in circulation. In empirical research, culture is regarded as a normal value standard, which is invariably inherited in different ethnic groups, social organizations, religious groups and so on (Alesina and Giuliano, 2015) [11]. However, whether theoretical or empirical studies, culture is generally regarded as a human belief or value standard. Due to the differences of population and geography in different parts of the world, culture has various forms of expression, and cultural diversity has also attracted much attention in the study of cultural economics. Specifically, cultural diversity includes the diversity of different cultural backgrounds, such as race, religious belief, language, growth environment and so on. Cultural diversity in economic research is often associated with identity and social trust. Cultural diversity can influence individual values and various social factors, including individualism, kinship ties, social trust level, creativity and technological complementarity and so on.

The cultural diversity studied in this paper refers to the diversity of clan surnames in China. At the county level, especially in the county with imperfect formal system, clan activities are still active (Tsai, 2007) [12]. Different clans have different cultural backgrounds and inheritance. Individuals belonging to different clans have different cognitive and value pursuit. The clan advocates mutual help within the clan, and because there is a natural sense of intimacy between the clans, individuals tend to trust the people of the same clan, while excluding outsiders. The clan's surname is the most intuitive external form to distinguish different clans, so the cultural diversity in this paper refers to the diversity of clan's surname. 


\subsection{The Current Research of Cultural Diversity and Economy}

Human society has different groups and social forms. Each group inherits and develops culture in its own way by means of different cultural manifestations, thus forming cultural diversity. Cultural diversity has rich connotations, mainly influenced by race, language, religious beliefs, living environment and other factors. In China, cultural diversity is mainly manifested in ethnic cultural diversity. Different cultures of different nationalities enrich the connotation of Chinese culture and are an important driving force for the progress of civilization and the exchange of economic activities. In recent years, with the development of research on the impact of culture on economic development, cultural diversity has become a hot topic for many scholars. In the existing literature on cultural diversity, there are different opinions on the role of cultural diversity in economy. Cultural diversity has both positive and negative effects.

One kind of literature finds that cultural diversity has hindered economic development. This kind of literature mainly holds that higher cultural diversity will increase the cost of communication, reduce the level of social identity and interpersonal trust, and hinder the cross-regional mobility of personnel to a certain extent. Tsui et al. (1992) [13] conducted a field study from the perspective of cultural diversity of entrepreneurship team, and found that cultural diversity is not conducive to the increase of enterprise output and the development of enterprise financing. Its mechanism is that cultural diversity hinders self-classification and social identity. Xu Xianxiang et al. (2015) [5] used the data of prefecture level and above in China to do empirical analysis. It was found that the cultural diversity of dialects would hinder the dissemination of knowledge and technology, thus having a negative impact on economic growth. Zhang Bo and Fan Chenchen (2018) [14] found that cultural diversity is not conducive to the prosperity of private finance at prefecture level in China. Its influence mechanism is that diversity reduces the social capital formed by the same regional culture and identity, thus increasing the transaction cost and risk of lending in private finance. Ding Congming et al. (2018) [15] argued that cultural and dialectal diversity overlaps with administrative divisions in history, which may underestimate the impact of diversity and reduce the accuracy of empirical analysis. Therefore, they synthesized the central city and the cities adjacent to it and constructed the city circle. Through empirical analysis, they found that dialect diversity hindered the formation of domestic market integration. Li Guangqin et al. (2017) [6] first analyzed the impact of linguistic diversity on the degree of regional opening up. He believed that the more diverse the languages, the lower the degree of regional opening up.

Another kind of literature holds that cultural diversity promotes economic development. This kind of literature mainly believes that cultural diversity brings about diverse ideas and backgrounds. Intercultural exchanges and collisions help to promote knowledge spillover and stimulate the formation of innovative ideas. Cox et al. (1991) [16] through experimental research, believed that 
cultural diversity can enrich the team's working life, thereby improving work efficiency, and has a positive effect on the performance of venture financing. $\mathrm{Li}$ Zhongfei et al. (2017) [17] used the survey data of world values to study the impact of cultural diversity on stock market prosperity in 56 countries (regions). Empirical analysis shows that cultural diversity can promote stock market prosperity in general. Liu Gang and Wang Zeyu (2016) [18] studied the impact of cultural diversity on Internet venture financing. They used the data of Internet product crowdfunding to conduct empirical analysis, and found that the cultural diversity of entrepreneurial teams is conducive to improving the performance of Internet financing. However, this promotion effect will decline after a certain turning point, and generally presents an inverted $\mathrm{U}$-shaped relationship, which can be adjusted by the education level and entrepreneurial experience of team members. Pan Yue et al. (2017) [3] studied the impact of cultural diversity on enterprise innovation. The number of dialects and dialect differentiation index were used to measure cultural diversity. Empirical results showed that cultural diversity promoted enterprise innovation.

\subsection{Measurement of Cultural Diversity}

Alesina and Giuliano (2015) [11] summarized three methods of measuring culture in empirical analysis: 1) Using statistical survey data including cultural variables. 2) Controlling other economic and institutional environmental factors. 3) Autonomous collection of experimental data. In the first method, the most commonly used are World Values Survey (WVS), China Comprehensive Social Survey (CGSS), China Family Tracking Survey (CFPS) and so on. The second method often uses immigration data to observe the economic output of immigrants from different countries and cultures in the same country. In addition, in order to eliminate the influence of self-selection of migration destination cleanly, empirical analysis samples often use the data of the second generation of migrants. The third method is mainly to design the experimental scheme, questionnaire and so on. People with different cultural backgrounds can participate in the experiment and the experimental data will be got for investigation. However, the experimental data involve limited audiences after all, and it is difficult to have a generally accepted conclusion whether the empirical results can be extended to the general society. Therefore, among the three methods, statistical survey data are the most widely used. This paper also uses statistical survey data to measure cultural diversity.

In terms of measurement content, because of the rich and abstract connotation of culture, the indicators of measurement are different, and the direction of measurement is often determined according to specific research perspectives. At present, scholars at home and abroad mainly measure cultural diversity in two directions.

One is to measure cultural diversity by the difference of beliefs or values from the essence of culture. Inglehart and Baker (2000) [19] used the survey data of world values to analyze the results of the survey by factor analysis. They divided 
values into two categories: social characteristics and personal characteristics, forming a two-dimensional cultural model. This is also the official indicator for measuring cultural diversity with data from the World Values Survey. On their basis, Li Zhongfei et al. (2017) [17] regards the scoring position of each country in the two-dimensional model as a binary vector, calculates the cultural distance based on these vectors, and then carries on the clustering, obtains the number and distance of clustering to represent the cultural diversity.

Second, from different perspectives of cultural connotation, the measurement of cultural diversity mainly includes ethnic diversity, religious diversity, linguistic diversity and birthplace diversity. Alesina and Ferrara (2005) [20] measured ethnic diversity at the urban and county levels in the United States and analyzed its impact on economic growth. Empirical analysis found that ethnic diversity hindered regional economic growth. Guo Yunnan and Wang Chunfei (2017) [21] found that the investment of public goods in villages with religious beliefs is higher in China's rural areas. They further subdivided religion. Empirical analysis shows that villages with Christian beliefs play a greater role in the investment of public goods in villages. Owen and Videras (2007) [22] found that although believers with religious beliefs are more willing to build environmental protection, different religious believers have different attitudes and ideas on specific construction. Qian (2013) [23] used birth nationality data of American urban residents to measure cultural diversity and analyze its impact on innovation. Böheim et al. (2014) [24] and Trax et al. (2015) [25] respectively used samples of Australian and German enterprises to carry out empirical research, and found that the diversity of workers' birthplaces has a significant promoting effect on the benefits of enterprises and workers.

Most domestic scholars measure cultural diversity from dialect. Xu Xianxiang et al. (2015) [5] used the Dictionary of Chinese Dialects as a data source to measure the dialect diversity in China. 2356 counties and cities with complete dialect information were sorted out and the dialect diversity index of 278 cities at prefecture level and above was calculated. This method of measuring cultural diversity is highly representative and has been directly cited by many scholars in the empirical study of cultural diversity (Pan Yue et al., 2017; Li Guangqin et al., 2017; Zhang Bo and Fan Chenchen, 2018) [3] [6] [14]. Ding Congming et al. (2018) [15] added minority dialects on the basis of Chinese dialects, taking into account the dialect data of all administrative divisions in China, making the measurement of dialect diversity more complete. This paper measures the diversity of clan surnames, and the measurement method will be introduced in the next section.

\section{Data Selection and Measurement of Indicators}

\subsection{Clan Surname Diversity}

\subsubsection{Data Sources}

Genealogy is a kind of cultural symbol, which records the genealogy and blood 
relationship of the clan and the ancestors, celebrities and deeds of the clan. It is also the external expression carrier of the patriarchal system and clan. The data to measure the diversity of clan surnames are derived from "Chinese Genealogy Catalogue: Knowledge Service Platform of Family Genealogy in Shanghai Library". The general catalogue covers all the Chinese genealogies in the world, extracts the content summary according to the content of the genealogies, and compiles a joint catalogue of Chinese genealogies. The compilation was started in 2000 and completed in 2008. It was included and published by Shanghai Library. The collection and distribution of Chinese genealogy also promoted the in-depth study of Chinese genealogy culture by scholars both at home and abroad. The genealogy itself is an important carrier of the cultural heritage of the Chinese nation and plays a special role of unity and cohesion for Chinese people at home and abroad. According to the statistics at the end of 2003, Shanghai Library has collected 76,781 genealogical catalogues from all over the world, deducting about $30 \%$ of the copies. There are 52,401 genealogical items and 608 surnames in Shanghai Library. So far, it has the largest number of genealogies and the most complete surnames in China. The genealogy catalogue is complete and detailed, including not only the name of the genealogy, the responsible person, the number of volumes, the age of the edition and other information, but also the family name, ancestors, hall names, celebrities of past dynasties and other more detailed information.

\subsubsection{Measurement Methods}

Cultural diversity has rich connotations, including the diversity of language, race, religion, birth environment and other factors. This paper studies the diversity of clan surnames at the county level. The clan is rooted in the Confucian culture and inherits the strict patriarchal cultural characteristics. The family bloodline is extended through the family name. Genealogy is an important external carrier inherited by the clan, which records the lineage, rules, ancestors, celebrities and deeds of the same clan and consanguineous group. Genealogical surnames, which distinguish different clans and represent different kinship, are the external manifestation of Chinese traditional clan concept. In this paper, the surname diversity index and the number of surnames in the genealogies in county were used as the index to measure the clan surname diversity in county.

There are two main methods for calculating diversity index by scholars at home and abroad. The first is to count the number of different categories as a direct index of diversity. The advantage of this method is that it only pays attention to the category, and the category situation will not change in a short time, so it has high stability. However, there may be some errors in this calculation method, which is equivalent to assuming that the status of each category is equal, without considering the differences of specific situations of different categories. Therefore, the second calculation method is more common, which combines the weight (usually population) into the calculation on the basis of the former. $\mathrm{Xu}$ Xianxiang et al. (2015) [5] defined the diversity index of dialects as the diversity 
of dialects used within a region, and calculated the diversity index by the number of dialects used in a region. In addition, considering the differences in the number of people using different dialects, they constructed the dialect diversity differentiation index of the city, and the calculation formula is as follows:

“Div_ $w_{i}=1-\sum_{j=1}^{N} S_{j i}^{2}$ ”. Among them, $S_{j i}$ represents the proportion of people who use $j$ dialect in $i$ city to the total urban population. This paper mainly refers to the calculation method of Xu Xianxiang's diversity index (2015) [5] and the Herfindahl index, which represents the degree of concentration. The measurement method of diversity index in this paper is calculated by subtracting Herfindahl index from 1 . The specific calculation method is as follows:

$$
\text { diversity }_{i}=1-\sum_{i=1}^{n}\left(X_{t i} / X_{i}\right)^{2}=1-\sum_{t=1}^{n} S_{t i}^{2}
$$

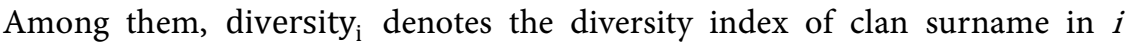
county; $X_{t i}$ denotes the number of genealogies with $\mathrm{t}$ surname in the total genealogies owned by $i$ county; $X_{i}$ denotes the number of genealogies in $i$ county; $S_{t i}=X_{t i} / X_{i}$ denotes the share of genealogies with t surname in $i$ county; and $\mathrm{n}$ denotes the number of surnames of genealogies in $i$ county. Obviously, the value of diversity $\mathrm{y}_{\mathrm{i}}$ ranges from 0 to 1 . The larger the value of diversity $_{i}$, the higher the diversity of genealogy surnames, the stronger the cultural diversity of the county. In the robustness test, the number of genealogy surnames owned by the county will be used as another measure of clan surname diversity.

\subsection{County Economic Development Performance}

\subsubsection{Data Sources}

Data to measure county economic development performance indicators are derived from night light brightness data published by the National Oceanic and Atmospheric Administration (NOAA). Since the publication of the data, night light brightness data has been regarded as an objective indicator to measure the economic development performance of countries and regions, which has been adopted by many empirical economic literatures. Compared with GDP, which is a traditional indicator of regional economic development, night light brightness data is obtained by satellite sensors, and the accuracy of the data is relatively high. However, the traditional GDP data are mostly obtained by human statistics, which is greatly disturbed by human factors. However, night light brightness has a range of values, the maximum value is 63 , which means that if the night light brightness of an area is actually greater than 63 , the value displayed in the data is still 63. Therefore, the luminance value of night light is 63 , which does not necessarily reflect the true luminance. However, for most underdeveloped countries, the problem of light saturation can be basically ignored. Wang Xianbin et al. (2017) [26] also pointed out that the use of light data to measure regional economic development in China is less affected by this problem.

\subsubsection{Measurement Methods}

In this paper, the performance of county economic development was measured 
by two methods using the night light brightness data from 2000 to 2012 . One is to directly measure the absolute value of the night light brightness data of the county, and the other is to measure the economic growth of the county by relative value, that is, the growth of the night light brightness of the county compared with the previous year.

\subsection{Major Control Variables}

In addition to the cultural diversity studied in this paper, the level of regional economic development is also affected by many factors, such as natural conditions, education level, factor input and so on. Based on the theory of economic development and the methods of previous studies, the control variables selected in this paper include land resources, labor resources, education level and capital investment. Among them, the common cultivated land area per capita is used to represent land resources; the population per unit of land area is used to represent labor resources; the number of students in primary and secondary schools per 10,000 people is used to represent education level; and the investment in fixed assets per unit of GDP is used to represent capital investment. The data come from county statistical yearbook of China and regional economic statistical yearbook of China.

\subsection{Descriptive Statistics of Variables}

Table 1 reports the results of variable descriptive statistics. From the results, we can see that the minimum and maximum luminance of county night light are 0.028 and 62.165 respectively, which are within the range of the values of the lighting data, so there is no measurement deviation due to the saturation of the night light data. The great difference of night light brightness indicates that there is a big regional gap in the economic development performance of counties in

Table 1. Descriptive statistics of variables.

\begin{tabular}{|c|c|c|c|c|c|c|}
\hline Variables & Definition & Observation & Mean & Std & Minimum & Maximum \\
\hline \multicolumn{7}{|c|}{ 1) Annual county data } \\
\hline nightlight & Night light brightness (range $0-63$ ) & 14,131 & 5.450 & 7.910 & 0.028 & 62.165 \\
\hline d_light & Annual growth of light intensity (\%) & 14,131 & 33.677 & 145.442 & -1100.975 & 1904.348 \\
\hline pceducate & $\begin{array}{l}\begin{array}{l}\text { Number of primary and secondary school students per } 10,000 \\
\text { people }\end{array}\end{array}$ & 13,581 & 785.163 & 747.191 & 0.030 & 3642.145 \\
\hline palabor & Population per unit of land area (10,000 people/square kilometers) & 13,652 & 170.172 & 258.965 & 0.000 & 1952.392 \\
\hline pdinvest & Investment in fixed assets per unit of GDP & 8377 & 0.464 & 0.296 & 0.007 & 7.127 \\
\hline pcgengdi & Per capita arable land area (ha./10,000 people) & 7925 & 234.614 & 468.871 & 0.000 & 7428.728 \\
\hline pcgdp & Per capita GDP (10,000 yuan) & 9079 & 0.653 & 1.362 & 0.000 & 29.527 \\
\hline \multicolumn{7}{|c|}{ 2) County time-point data } \\
\hline diversity & Clan surname diversity index & 1087 & 0.607 & 0.353 & 0 & 0.983 \\
\hline surname_count & Number of clan surnames & 1087 & 10.850 & 16.013 & 1 & 110 \\
\hline
\end{tabular}


China. From the annual growth of light brightness, the average value is 33.677 , which indicates that the economic situation of the counties in China is developing in the direction of growth as a whole. The maximum value of clan surname diversity index is 0.983 , and the average value is higher than 0.5 , while the minimum number of clan surnames is 1 , and the maximum number is 110 . It can be seen that the clan surnames in counties of China are quite diverse, and the diversity of clan surnames in different counties is quite different.

\section{The Diversity of Clan Surnames and the Performance of County Economic Development}

\subsection{Basic Model Construction}

In order to study the impact of clan surname diversity on county economic development performance, this paper uses night light brightness data at county level as explained variable, clan surname diversity at county level as explanatory variable, and ordinary least square (OLS) was used for regression, and the regression equation was constructed as follows:

$$
\text { nightlight }_{i}=\alpha_{0}+\alpha_{1} \text { diversity }_{i}+\alpha_{2} X_{\mathrm{i}}+\mu_{i}
$$

Among them, $i$ represents each county; nightlight ${ }_{i}$ represents the performance of economic development of $i$ county, measured by night light brightness

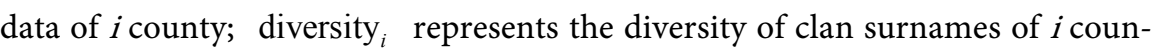
ty; $X_{\mathrm{i}}$ is a group of control variables, including resources, labor, education level, capital, etc; and $\mu_{i}$ is a random interference item.

\subsection{Regression Results}

Table 2 reports the estimated results of the baseline regression Equation (4.1). From the regression results, we can see that the regression coefficient of clan surnames for county economic development performance indicators is positive, and all pass the test of $1 \%$ significance level. This result remains stable with or without controlling variables, indicating that the diversity of clan surnames has a positive impact on county economic development. Among them, the first column reports the regression results of introducing only the diversity of clan surnames. At this time, the regression coefficient of the diversity index of clan surnames is 2.939 , which means that for every $1 \%$ increase in the diversity of clan surnames, the night light brightness of county will increase by $2.939 \%$.

Columns 2 - 5 report the estimated results of stepwise introducing control variables for regression. In column 2 - 5, the county natural resources, labor resources, education level and capital endowment are introduced. From the results, we can see that the regression coefficients of each variable are almost significant at the level of $1 \%$ significance. The Fifth Column reports the regression results after introducing all variables. At this time, the regression coefficient of clan surname diversity is 0.617 , which is 2.322 units lower than the regression coefficient in the first column. It shows that the introduced control variables can better eliminate the impact of other factors on economic development. This also 
Table 2. Benchmark regression results.

\begin{tabular}{cccccc}
\hline & $(1)$ & $(2)$ & $(3)$ & $(4)$ & $(5)$ \\
\hline & nightlight & nightlight & nightlight & nightlight & nightlight \\
\hline diversity & $2.939^{* * *}$ & $1.152^{* * *}$ & $0.886^{* * *}$ & $0.636^{* * *}$ & $0.617^{* * *}$ \\
& $(0.187)$ & $(0.153)$ & $(0.141)$ & $(0.138)$ & $(0.146)$ \\
pcgengdi & & $0.001^{* * *}$ & $0.003^{* * *}$ & $0.001^{* * *}$ & $0.001^{* * *}$ \\
& & $(0.000)$ & $(0.000)$ & $(0.000)$ & $(0.000)$ \\
palabor & & $0.007^{* * *}$ & $0.010^{* * *}$ & $0.009^{* * *}$ \\
& & & $(0.000)$ & $(0.000)$ & $(0.000)$ \\
pceducate & & & & $0.003^{* * *}$ & $0.003^{* * *}$ \\
& & & & $(0.000)$ & $(0.000)$ \\
pdinvest & & & & & $0.344^{*}$ \\
& & & & & \\
_cons & $3.666^{* * *}$ & $3.118^{* * *}$ & $0.689^{* * *}$ & $-0.357^{* * *}$ & $-0.443^{* * *}$ \\
& $(0.131)$ & $(0.113)$ & $(0.122)$ & $(0.128)$ & $(0.160)$ \\
$\mathrm{N}$ & 14131 & 7925 & 7925 & 7880 & 7428 \\
$\mathrm{R}^{2}$ & 0.017 & 0.015 & 0.166 & 0.217 & 0.204 \\
\hline
\end{tabular}

Standard errors in parentheses. ${ }^{*} \mathrm{p}<0.10,{ }^{* *} \mathrm{p}<0.05,{ }^{* * *} \mathrm{p}<0.01$.

means that after controlling for other factors affecting economic development, the night light brightness of county will increase by $0.617 \%$ for every $1 \%$ increase in the diversity of clan surnames. In addition, other indicators of control variables have a positive impact on county economic development performance, which is also consistent with the expected results. In a word, the results of benchmark regression are consistent with the theoretical expectations. The diversity of clan surnames in counties has a significant positive impact on the economic development performance measured by night light brightness data. The more diverse the clan surnames in the county, the better the economic development performance.

\subsection{Robustness Test}

\subsubsection{Regression of Economic Growth}

In this paper, we use the night light brightness of counties from 2000 to 2012 to measure the economic development, which lacks the measurement of economic development changes. Economic development changes can be measured by growth volume and growth rate. Considering that the growth space of the county with brighter original lights is smaller, and the growth rate will be lower and lower if the base is large and the growth volume is small, this does not mean that the economic development of the county is worse. Therefore, the change of county economic development should not be measured by the growth rate of night light brightness. Night light brightness growth volume can more accurately express the changes of economic development. In this paper, the annual growth 
volume of the county's night light intensity is used to measure the county's economic growth and further explore the impact of the diversity of clan surnames on the county's economic growth. The regression equation is constructed as follows:

$$
\text { d_light }_{i}=\beta_{0}+\beta_{1} \text { diversity }_{i}+\beta_{2} X_{i}+\varphi_{i}
$$

Among them, d_light ${ }_{i}$ indicates the increase of night light brightness in $i$ county compared with the previous year (unit: percentage); diversity ${ }_{i}$ represents the diversity index of clan surnames in $i$ county, $X_{i}$ represents a group of control variables, and $\varphi_{i}$ represents random interference items.

From the regression results of Table 3, we can see that the diversity of clan surnames still has a positive impact on the county economic growth, and it passes the test of $5 \%$ significance level as a whole.

\subsubsection{Regression of GDP Indicator}

The traditional index of economic development performance is gross domestic product (GDP). This paper uses the per capita GDP (unit: 10,000 yuan) of the county as the explained variable to carry out regression test on the basis of the basic regression Equation (4.1). The results are stable. The diversity of clan surnames has a promoting effect on the economic development performance of the county.

From the regression results of Table 4, we can see that the impact of clan surname diversity on economic development measured by GDP per capita is significantly

Table 3. Regression results of economic growth.

\begin{tabular}{|c|c|c|c|c|c|}
\hline & (1) & (2) & (3) & (4) & (5) \\
\hline & d_light & d_light & d_light & d_light & d_light \\
\hline \multirow[t]{2}{*}{ diversity } & $17.801^{* * *}$ & $9.829^{* * *}$ & $9.120^{\star *}$ & 5.491 & $8.535^{\star *}$ \\
\hline & (3.464) & (3.606) & (3.607) & (3.613) & (3.751) \\
\hline \multirow[t]{2}{*}{ pcgengdi } & & $0.048^{* * *}$ & $0.053^{* * *}$ & $0.029^{* * *}$ & $0.028^{* * *}$ \\
\hline & & $(0.003)$ & $(0.003)$ & $(0.004)$ & $(0.004)$ \\
\hline \multirow[t]{2}{*}{ palabor } & & & $0.020^{* * *}$ & $0.045^{\star * *}$ & $0.046^{\star * *}$ \\
\hline & & & $(0.005)$ & $(0.006)$ & $(0.006)$ \\
\hline \multirow[t]{2}{*}{ pceducate } & & & & $0.032^{* * *}$ & $0.026^{* * *}$ \\
\hline & & & & $(0.003)$ & $(0.003)$ \\
\hline \multirow[t]{2}{*}{ pdinvest } & & & & & $29.181^{\star \star \star}$ \\
\hline & & & & & $(4.837)$ \\
\hline \multirow[t]{2}{*}{ _cons } & $22.869^{* * *}$ & $19.732^{\star * *}$ & $13.251^{* * *}$ & 1.242 & $-12.206^{\star * *}$ \\
\hline & $(2.432)$ & $(2.663)$ & $(3.127)$ & $(3.353)$ & $(4.121)$ \\
\hline $\mathrm{N}$ & 14131 & 7925 & 7925 & 7880 & 7428 \\
\hline $\mathrm{R}^{2}$ & 0.002 & 0.038 & 0.040 & 0.052 & 0.052 \\
\hline
\end{tabular}

Standard errors in parentheses. ${ }^{*} \mathrm{p}<0.10,{ }^{* *} \mathrm{p}<0.05,{ }^{* * *} \mathrm{p}<0.01$. 
Table 4. Regression results of GDP indicator.

\begin{tabular}{cccccc}
\hline & $(1)$ & $(2)$ & $(3)$ & $(4)$ & $(5)$ \\
\hline \multirow{2}{*}{ diversity } & pcgdp & pcgdp & pcgdp & pcgdp & pcgdp \\
& $0.220^{* * *}$ & $0.282^{* * *}$ & $0.316^{* * *}$ & $0.243^{* * *}$ & $0.238^{* * *}$ \\
& $(0.041)$ & $(0.032)$ & $(0.031)$ & $(0.030)$ & $(0.032)$ \\
pcgengdi & & $0.001^{* * *}$ & $0.001^{* * *}$ & $0.001^{* * *}$ & $0.001^{* * *}$ \\
& & $(0.000)$ & $(0.000)$ & $(0.000)$ & $(0.000)$ \\
palabor & & & $-0.001^{* * *}$ & $-0.000^{* * *}$ & $-0.000^{* * *}$ \\
& & & $(0.000)$ & $(0.000)$ & $(0.000)$ \\
pceducate & & & & $0.001^{* * *}$ & $0.001^{* * *}$ \\
& & & & $(0.000)$ & $(0.000)$ \\
pdinvest & & & & & $-0.170^{* * *}$ \\
& & & & & $(0.041)$ \\
cons & $0.520^{* * *}$ & 0.032 & $0.349^{* * *}$ & 0.045 & $0.124^{* * *}$ \\
& $(0.028)$ & $(0.024)$ & $(0.027)$ & $(0.028)$ & $(0.035)$ \\
$\mathrm{R}^{2}$ & 9079 & 7925 & 7925 & 7880 & 7428 \\
\hline & 0.003 & 0.302 & 0.344 & 0.416 & 0.414 \\
\hline
\end{tabular}

Standard errors in parentheses. ${ }^{*} \mathrm{p}<0.10,{ }^{* *} \mathrm{p}<0.05,{ }^{* * *} \mathrm{p}<0.01$.

positive. The first column reports the results of not adding control variables, when the regression coefficient of clan surname diversity index is 0.220 , and passed the test of significance level of $1 \%$. After adding all control variables, the regression coefficient of clan surname diversity index is 0.238 , which means that the per capita GDP of county will increase by 23.8 yuan for every $1 \%$ increase in clan surname diversity.

\subsubsection{Regression of the Number of Clan Surnames}

In this paper, Herfindahl index is used to measure the concentration of clan surnames in benchmark model regression, and then one minus the concentration degree is used to get the measure index of diversity. In addition, referring to the method of Xu Xianxiang et al. (2015) [5] to measure the diversity of dialects, this paper uses the number of genealogy surnames in county as another indicator to measure the diversity of clan surnames, and carries out a regression test:

$$
\begin{gathered}
\text { nightlight }_{i}=\gamma_{0}+\gamma_{1} \text { surname_count }_{i}+\gamma_{2} X_{i}+\sigma_{i} \\
\text { d_light }_{i}=\delta_{0}+\delta_{1} \text { surname_count }_{i}+\delta_{2} X_{i}+\omega_{i} \\
\text { pcgdp }_{i}=\theta_{0}+\theta_{1} \text { surname_count }_{i}+\theta_{2} X_{i}+\rho_{i}
\end{gathered}
$$

From the regression results of Table 5, we can see that the clan surnames diversity measured by the number of genealogy surnames in county still has a positive impact on county economy, and all pass the test of 5\% significance level. Among them, the first and the second are listed as the regression results of the influence of clan surname diversity on county night light brightness, the third 
Table 5. Regression results of the number of clan surnames.

\begin{tabular}{|c|c|c|c|c|c|c|}
\hline & (1) & (2) & (3) & (4) & (5) & (6) \\
\hline & nightlight & nightlight & d_light & d_light & pcgdp & pcgdp \\
\hline \multirow[t]{2}{*}{ surname_count } & $0.083^{* * *}$ & $0.026^{* * *}$ & $0.538^{\star * *}$ & $0.173^{\star *}$ & $0.008^{* * *}$ & $0.004^{* * *}$ \\
\hline & $(0.004)$ & $(0.003)$ & $(0.076)$ & $(0.083)$ & $(0.001)$ & $(0.001)$ \\
\hline \multirow[t]{2}{*}{ pcgengdi } & & $0.001^{* * *}$ & & $0.028^{* * *}$ & & $0.001^{\star * *}$ \\
\hline & & $(0.000)$ & & $(0.004)$ & & $(0.000)$ \\
\hline \multirow[t]{2}{*}{ palabor } & & $0.009^{* * *}$ & & $0.047^{\star * *}$ & & $-0.000^{* * *}$ \\
\hline & & $(0.000)$ & & $(0.006)$ & & $(0.000)$ \\
\hline \multirow[t]{2}{*}{ pceducate } & & $0.003^{* * *}$ & & $0.026^{\star * *}$ & & $0.001^{* * *}$ \\
\hline & & $(0.000)$ & & $(0.003)$ & & $(0.000)$ \\
\hline \multirow[t]{2}{*}{ pdinvest } & & 0.297 & & $28.346^{* * *}$ & & $-0.194^{\star * *}$ \\
\hline & & $(0.187)$ & & $(4.818)$ & & $(0.041)$ \\
\hline \multirow[t]{2}{*}{ _cons } & $4.550^{\star * *}$ & $-0.326^{* *}$ & $27.840^{* * *}$ & $-8.586^{* *}$ & $0.572^{\star * *}$ & $0.234^{* * *}$ \\
\hline & $(0.079)$ & $(0.134)$ & $(1.476)$ & $(3.461)$ & $(0.017)$ & $(0.029)$ \\
\hline $\mathrm{N}$ & 14131 & 7428 & 14131 & 7428 & 9079 & 7428 \\
\hline $\mathrm{R}^{2}$ & 0.028 & 0.209 & 0.004 & 0.052 & 0.008 & 0.413 \\
\hline
\end{tabular}

Standard errors in parentheses. ${ }^{*} \mathrm{p}<0.10,{ }^{* *} \mathrm{p}<0.05,{ }^{* *} \mathrm{p}<0.01$.

and the fourth are listed as the regression results of the influence of clan name diversity on the county night light brightness annual growth, and the regression results of per capita GDP are listed in the fifth and sixth columns. The regression coefficient of the second column is 0.026 , which means that the brightness of county night light will increase by 0.026 units for each additional surname of county genealogy. The regression coefficient of the fourth column is 0.173 , which shows that the annual growth of night light brightness (unit: percentage) will increase by $0.173 \%$ for each additional surname of county genealogy. From the per capita GDP, the regression coefficient of the sixth column is 0.004 , which indicates that the per capita GDP of the county will increase by 40 yuan for each additional surname of county genealogy.

\section{Research Conclusions}

The issue of economic development has always been the focus of people's attention, and studies in this field are endless. Most studies focus on economic growth from knowledge, technology and other factors of production. As a broad and abstract concept, culture has been less involved in empirical studies of economics in the past because it is difficult to quantify. Over the past decade, the research on the impact of culture on economy has been deepening, and new progress has been made in empirical research. Many scholars at home and abroad pay more attention to the economic impact of cultural diversity. This paper studies the economic development performance of counties in China. 
Clan is an active social organization at the county level, especially in areas with imperfect formal system. It plays an important cultural and social function (Tsai, 2007; Ding Congming et al., 2018) [12] [15]. However, there is no empirical research on economic development from the perspective of clan surname diversity. Although the concept of clan in China is deeply influenced by Confucianism, different clans have different historical and cultural backgrounds and cultural inheritance, which are reflected in ancestral precepts, family rules and other carriers. The surname of the genealogy can distinguish different clans, so this paper constructs the clan surname diversity index of each county in China. According to the Chinese Genealogy, this paper collects and calculates the surname number and surname diversity index of genealogy in 1087 counties in 27 provinces and 270 prefecture-level cities in China, so as to measure the diversity of clan surnames in county.

This paper studies the impact of clan surname diversity on county economic development performance. The performance of county economic development is measured by night light brightness data of county, which spans from 2000 to 2012, and is tested by traditional GDP in robustness test. Empirical analysis shows that the diversity of clan surnames has a significant positive impact on the performance of county economic development. The results of benchmark regression show that for every $1 \%$ positive change of clan surname diversity index in county, the economic development performance will change by $2.939 \%$. The results of this study belong to the literature that cultural diversity is beneficial to economic growth. To some extent, this study provides a new perspective to study the economic impact of cultural diversity.

\section{Conflicts of Interest}

The author declares no conflicts of interest regarding the publication of this paper.

\section{References}

[1] Luo, H. (2009) Culture and Economic Growth: A Preliminary Analysis Framework. Economic Review, 1, 113-121.

[2] Guiso, L., Sapienza, P. and Zingales, L. (2006) Does Culture Affect Economic Outcomes? Journal of Economic Perspectives, 20, 23-48.

[3] Pan, Y., Xiao, J.L. and Dai, Y.Y. (2017) Cultural Diversity and Enterprise Innovation: A Dialect-Based Perspective. Financial Research, No. 10, 150-165.

[4] Weber, M. (1986) Protestant Ethics and Capitalist Spirit. Sichuan People's Publishing House, Chengdu.

[5] Xu, X.X., Liu, Y.Y. and Xiao, Z.K. (2015) Dialects and Economic Growth. Economic Journal, No. 2, 1-32.

[6] Li, G.Q., Cao, J.H. and Shao, S. (2017) Regional Differences in Linguistic Diversity and China's Opening Up. World Economy, No. 3, 146-170.

[7] Guo, Y.N., Zhang, L.Y. and Yao, Y. (2013) Clan Network, Financing and Farmers' Self-Employment. Financial Research, No. 9, 136-149.

[8] Guo, Y.N., Yao, Y. and Foltz, J. (2014) Clan Network and Village Income Distribu- 
tion. Managing the World, No. 1, 73-89.

[9] Zhang, C. (2016) Culture and the Economy: Clan, Entrepreneurship, and Development of the Private Sector in China. SSRN Electronic Journal.

[10] Greif, A. and Tabellini, G. (2017) The Clan and the Corporation: Sustaining Cooperation in China and Europe. Journal of Comparative Economics, 45, 1-35.

[11] Alesina, A. and Giuliano, P. (2015) Culture and Institutions. Journal of Economic Literature, 53, 898-944. https://doi.org/10.1257/jel.53.4.898

[12] Tsai, L. (2007) Solidary Groups, Informal Accountability, and Local Public Goods Provision in Rural China. The American Political Science Review, 101, 355-372. https://doi.org/10.1017/S0003055407070153

[13] Tsui, A., Egan, T. and Iii, C. (1992) Being Different: Relational Demography and Organizational Attachment. Administrative Science Quarterly, 37, 549-579. https://doi.org/10.2307/2393472

[14] Zhang, B. and Fan, C.C. (2018) Cultural Diversity and Folk Finance: Empirical Research Based on Dialect Perspective. Financial Research, No. 7, 69-89.

[15] Ding, C.M., Ji, Z.L., Lei, Y. and Liang, Z.Q. (2018) Dialect Diversity and Market Integration: From the Perspective of Urban Circle. Economic Research, No. 11, 148-167.

[16] Cox, T., Lobel, S. and Mcleod, P. (1991) Effects of Ethnic Group Cultural Differences on Cooperative and Competitive Behavior on a Group Task. Academy of Management Journal, 34, 827-847.

[17] Li, Z.F., Tang, Z.Q. and Liu, Q.W. (2017) Cultural Diversity and Stock Market Prosperity: An Empirical Analysis Based on WVS Data. International Financial Research, No. 5, 68-77.

[18] Liu, G. and Wang, Z.Y. (2016) Cultural Diversity of Entrepreneurial Teams and Internet Venture Finance: An Empirical Analysis Based on Product Crowd Financing Data. Finance and Trade Economy, 37, 113-128.

[19] Inglehart, R. and Baker, W. (2000) Modernization, Cultural Change, and the Persistence of Traditional Values. American Sociological Review, 65, 19-51. https://doi.org/10.2307/2657288

[20] Alesina, A. and Ferrara, E. (2005) Ethnic Diversity and Economic Performance. Journal of Economic Literature, 43, 762-800. https://doi.org/10.1257/002205105774431243

[21] Guo, Y.N. and Wang, C.F. (2017) Investment in Religion and Public Goods in Rural China. Economics (Quarterly), No. 4, 57-78.

[22] Owen, L. and Videras, J. (2007) Culture and Public Goods: The Case of Religion and the Voluntary Provision of Environmental Quality. Journal of Environmental Economics Management, 54, 162-180. https://doi.org/10.1016/j.jeem.2007.04.001

[23] Qian, H. (2013) Diversity versus Tolerance: The Social Drivers of Innovation and Entrepreneurship in US Cities. Urban Studies, 50, 2718-2735.

[24] René, B., Horvath, T. and Mayr, K. (2014) Birthplace Diversity and Productivity Spill-Overs in Firms. Economics Papers, Vienna.

[25] Trax, M., Brunow, S. and Suedekum, J. (2015) Cultural Diversity and Plant-Level Productivity. Regional Science and Urban Economics, 53, 85-96. https://doi.org/10.1016/j.regsciurbeco.2015.05.004

[26] Wang, X.B., Huang, L.X., Xu, X.X. and Li, J. (2017) Dynamic Trend Revaluation of China's Regional Economic Gap: An Investigation Based on Satellite Light Data. Economics (Quarterly), No. 3, 24-43. 